Bài báo khoa học

\title{
Đánh giá tình hình thực hiện Cơ chế tín chỉ chung JCM tại Việt Nam: Kinh nghiệm để tiến tới triển khai Điều 6 của Thỏa thuận Paris về biến đổi khí hậu
}

\section{Nguyễn Thành Công ${ }^{*}$, Trần Tiến Dũng²}

1 Cục Biến đổi khí hậu; tcongnguyen90@gmail.com

2 Tổng cục Khí tượng Thủy văn; tdung117@gmail.com

* Tác giả liên hệ: tcongnguyen90@gmail.com; Tel.: +84-829906696

Ban Biên tập nhận bài: 8/6/2020; Ngày phản biện xong: 22/7/2020; Ngày đăng: 25/7/2020

Tóm tắt: Theo Đóng góp do quốc gia tự quyết định (NDC), Việt Nam cam kết cắt giảm $8 \%$ lượng phát thải khí nhà kính vào năm 2030 bằng nguồn lực trong nước và có thể cắt giảm $25 \%$ nếu có sự hỗ trợ tài chính, công nghệ, tăng cường năng lực của quốc tế thông qua các hoạt động hợp tác đa phương, song phương và thực hiện các cơ chế trong Thỏa thuận Paris về biến đồi khí hậu. Cơ chế tín chỉ chung JCM là ví dụ điển hình cho hoạt động hợp tác tiếp cận theo Điều 6.2 trong Thỏa thuận Paris, quy định về việc trao đổi nỗ lực giảm nhẹ quốc tế (ITMO). Bài báo sẽ cung cấp thông tin và đánh giá tình hình thực hiện Cơ chế JCM tại Việt Nam, cũng như phân tích mối liên hệ giữa Cơ chế JCM và Điều 6 của Thỏa thuận Paris về biến đổi khí hậu. Từ đó, kết quả của bài báo sẽ cung cấp cơ sở cho các nhà hoạch định chính sách trong việc xây dựng các văn bản quy phạm pháp luật có liên quan, tạo sự chuẩn bị tiến tới triển khai các cơ chế mới trong Thỏa thuận Paris về biến đổi khí hậu, góp phần giúp Việt Nam đạt được cam kết quốc tế về giảm nhẹ phát thải khí nhà kính.

Từ khóa: Cơ chế tín chỉ chung; Giảm nhẹ phát thải khí nhà kính; Thỏa thuận Paris về biến đổi khí hậu.

\section{Mở đầu}

Cơ chế JCM là cơ chế Chính phủ Nhật Bản đề xuất đối với các quốc gia đang phát triển nhằm thúc đẩy việc chuyển giao và phổ biến các công nghệ phát thải các-bon thấp để hướng tới tăng trưởng xanh ở nước sở tại và hỗ trợ thực hiện cam kết quốc tế về giảm nhẹ phát thải khí nhà kính của Nhật Bản. Từ năm 2013 đến nay, đã có 17 quốc gia tham gia vào Cơ chế JCM trên thế giới với tổng cộng 69 phương pháp luận, 51 dự án đăng ký, tập trung vào lĩnh vực tiết kiệm năng lượng. Trong đó, 30 dự án đã được cấp tín chỉ với lượng tín chỉ là 22.197 [1].

Để triển khai thực hiện JCM, Nhật Bản và các nước đối tác tiến hành ký kết Thỏa thuận ghi nhớ hợp tác song phương giữa hai Chính phủ. Chính phủ hai nước thành lập Ủy ban Hỗn hợp giữa hai nước để tiến hành xây dựng và ban hành các quy định và hướng dẫn thực hiện. Các quy định và hướng dẫn bao gồm các nội dung: Công nhận Bên thứ ba; Đề xuất và phê duyệt phương pháp luận; Đăng ký và phê duyệt dự án; Thực hiện và cấp tín chỉ cho dự án. Để hỗ trợ đầu tư thực hiện các dự án tại các nước tham gia, chính phủ Nhật Bản tiến hành hỗ trợ theo hai hình thức:

Bộ Môi trường Nhật Bản hỗ trợ tối đa $50 \%$ vốn đầu tư cho công nghệ ban đầu. Đối với các dự án có công nghệ tương tự đã được tài trợ, cam kết hỗ trợ sẽ giảm dần. Cụ thể, nếu các dự án có công nghệ tương tự, mức hỗ trợ tối đa là $40 \%$ cho dự án thứ 2 và 3 và $30 \%$ cho dự án 
thứ 4 trở đi. Trung tâm môi trường toàn cầu GEC được Bộ Môi trường Nhật Bản giao là cơ quan đầu mối, xét duyệt các đề xuất dự án nhận được hỗ trợ để tham gia Cơ chế JCM [2]. Quy trình hỗ trợ từ phía Bộ Môi trường Nhật Bản trong Cơ chế JCM được thể hiện tại Hình 1.

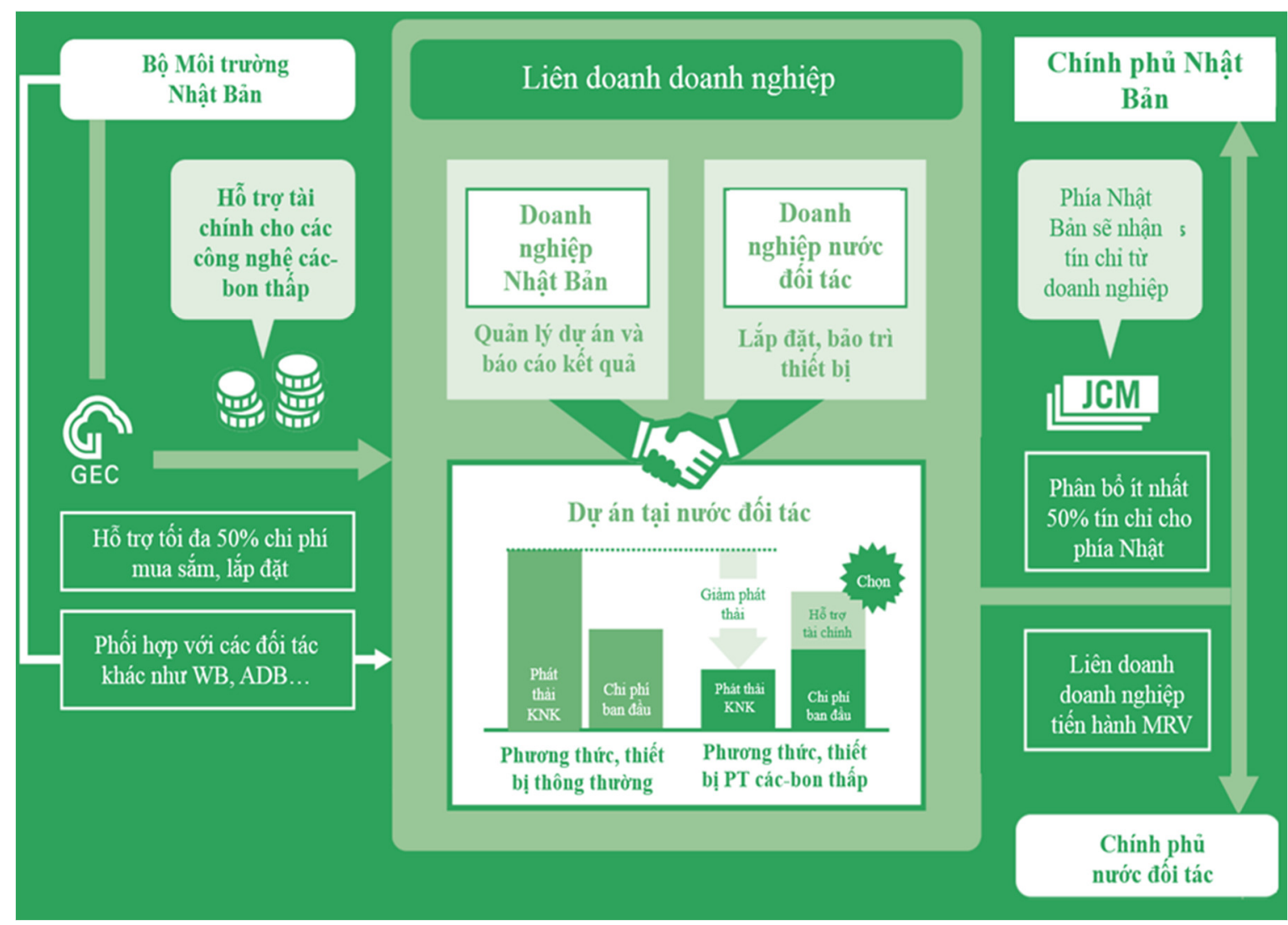

Hình 1. Quy trình hỗ trợ tài chính từ phía Bộ Môi trường Nhật Bản [3].

Cụ thể, một doanh nghiệp phía Nhật Bản và một doanh nghiệp phía nước sở tại sẽ tiến hành hợp tác liên doanh, xây dựng đề xuất dự án đầu tư và nộp xin hỗ trợ từ phía Nhật Bản thông qua Trung tâm GEC [3]. Doanh nghiệp Nhật Bản sẽ đóng vai trò quản lý dự án và trong khi đó doanh nghiệp nước sở tại sẽ tiến hành lắp đặt, bảo trì các thiết bị thuộc dự án. Các dự án nhận được hỗ trợ phải thỏa mãn các yêu cầu về môi trường, giảm nhẹ phát thải khí nhà kính và đặc biệt, cần đáp ứng tiêu chí về hiệu quả chi phí. Theo đó, Trung tâm GEC chỉ chấp thuận các đề xuất mà có mức chi phí giảm phát thải ít hơn JPY 4.000/tấn $\mathrm{CO}_{2}$ tđ, tương đương gần $880.000 \mathrm{VNĐ/tấn} \mathrm{CO}_{2}$ tđ.

Một phương thức hỗ trợ khác là từ Bộ Kinh tế, Thương mại và Công nghiệp Nhật Bản và Tổ chức Phát triển Công nghệ và Năng lượng mới (NEDO) cam kết $100 \%$ vốn đầu tư cho công nghệ, nhưng nước sở tại phải mua lại sau thời gian thí điểm hoặc trình diễn của dự án (3 năm) với mức chiết khấu thông thường (mức chiết khấu 23\%) [4]. Các dự án thuộc phương thức hỗ trợ này thường mang tính chất thí điểm, trình diễn công nghệ để tạo cơ sở nhân rộng trong tương lai. Hỗ trợ tài chính từ Bộ Kinh tế, Thương mại và Công nghiệp Nhật Bản thường sẽ thông qua các dự án đầu tư vốn ODA và vì vậy các đối tác thực hiện thường là các cơ quan, đơn vị thuộc Chính phủ các nước.

Sau khi tiến hành đăng ký và thực hiện dự án, các bên tham gia thảo luận và thống nhất về việc phân chia tín chỉ hay lượng giảm phát thải giữa các bên liên quan. Hiện nay, tất cả các quốc gia đều quy định các bên tham gia dự án tự xác định tỉ lệ phân bổ tín chỉ các-bon, căn cứ theo đóng góp từ mỗi bên và có thể đóng góp một phần tín chỉ cho 2 quốc gia. Duy chỉ có In-đô-nê-xia vào ngày 14/4/2016 đã tiến hành sửa đổi hướng dẫn thực hiện trong đó quy định ít nhất $10 \%$ tín chỉ thu được từ dự án JCM phải phân bổ cho phía Indonesia. 


\section{Phương pháp đánh giá}

\subsection{Phuoong pháp đánh giá tình hình thực hiện Cơ chế tín chỉ chung JCM tại Việt Nam}

Việc đánh giá tình hình thực hiện Cơ chế tín chỉ chung JCM tại Việt Nam được thực hiện thông qua các bước sau:

Bước 1: Rà soát, phân tích văn bản liên quan và kết quả giảm nhẹ của dự án JCM.

Các văn bản được rà soát và phân tích bao gồm: các văn bản pháp luật Việt Nam có liên quan về Cơ chế JCM, các thỏa thuận quốc tế, các kết quả đàm phán từ các cuộc họp kỹ thuật. Các kết quả giảm nhẹ của các dự án JCM từ năm 2013 cũng được phân tính, định lượng, xem xét ở các khía cạnh tài chính, lợi ích...

Bước 2: Tham vấn các đơn vị, cơ quan trực thuộc Chính phủ Việt Nam có đại diện tham gia Ủy ban Hỗn hợp.

Xin ý kiến từ các Bộ: Tài nguyên và Môi trường, Kế hoạch và Đầu tư, Tài chính, Khoa học và Công nghệ, Công Thương, Xây dựng, Giao thông vận tải, Nông nghiệp và Phát triển nông thôn về các thuận lợi, tồn tại và khó khăn từ về việc quản lý, hoạch định chính sách liên quan đến việc thực hiện Cơ chế JCM và các cơ chế khác thuộc khuôn khổ Điều 6 của Thỏa thuận Paris về biến đổi khí hậu.

Bước 3: Tham vấn các đơn vị trực tiếp thực hiện dự án phía Việt Nam.

Phỏng vấn đại diện các đơn vị trực tiếp tham gia dự án phía Việt Nam (gồm 14 đơn vị, doanh nghiệp) với các câu hỏi tập trung về việc đánh giá tình hình tiếp nhận tài chính, đánh giá công nghệ tiếp nhận, các khó khăn, thuận lợi trong việc triển khai thực hiện, cũng như đánh giá năng lực tiếp cận các cơ chế tạo tín chỉ khác, sự hiểu biết về các cam kết giảm nhẹ phát thải khí nhà kính trong tương lai.

Bước 4: Tham vấn các đơn vị tư vấn, chuyên gia tham gia thẩm định dự án và phương pháp luận của Cơ chế JCM.

Tiến hành tham vấn các đơn vị, chuyên gia tư vấn có nhiều năm kinh nghiệm về triển khai các cơ chế tạo tín chỉ như Cơ chế phát triển sạch CDM, Cơ chế JCM về khả năng mở rộng và chuyển đổi cho giai đoạn sau 2020.

\section{Bước 5: Tổng hợp, phân tích ý kiến}

Tổng hợp và phân tích các kết quả rà soát chính sách và tham vấn các bên liên quan, để từ đó rút ra được các bài học và kiến nghị thực hiện Cơ chế $\mathrm{JCM}$ và các cơ chế khác thuộc Thỏa thuận Paris về biến đổi khí hậu.

\subsection{Mối liên hệ giữa Co chế JCM và Điều 6 của Thỏa thuận Paris về biến đổi khí hậu}

Với việc thông qua Thỏa thuận Paris về biến đổi khí hậu vào năm 2016, các cam kết quốc tế về giảm nhẹ phát thải khí nhà kính của Việt Nam trở nên mang tính ràng buộc. Theo đó, trong NDC, Việt Nam cam kết với nguồn lực quốc gia tới năm 2030 giảm $8 \%$ lượng phát thải khí nhà kính so với năm cơ sở, tập trung vào 4 lĩnh vực chính bao gồm năng lượng, chất thải, nông nghiệp, LULUCF, và có thể giảm tới $25 \%$ nếu có sự hỗ trợ từ phía quốc tế [5]. Thỏa thuận Paris về biến đổi khí hậu cũng cho phép các Bên hợp tác thực hiện các NDC đối với việc giảm phát thải KNK thông qua các cơ chế được nêu tại Điều 6 [6]. Cụ thể trong Điều 6 , ba phương thức hợp tác chính đã được đề xuất:

Điều 6.2 quy định về trao đổi quốc tế các kết quả giảm nhẹ (ITMO) cho phép các Bên hợp tác song phương hoặc đa phương trực tiếp với nhau mà không cần qua một cơ chế quốc tế thống nhất. Ví dụ, các hoạt động giảm nhẹ biến đổi khí hậu được thực hiện ở một quốc gia, có thể được chuyển sang một quốc gia khác và sẽ được tính vào NDC của quốc gia đó. Quy định thực hiện sẽ phụ thuộc vào sự đồng thuận và thống nhất giữa các Bên tham gia [7].

Điều 6.4 quy định về cơ chế đóng góp giảm nhẹ phát thải khí nhà kính và hỗ trợ phát triển bền vững $(\mathrm{SDM})$. Khác với các công cụ được sử dụng trong hợp tác song phương, đa phương trực tiếp, cơ chế mới được đề xuất này sẽ được giám sát bởi một cơ quan do Hội nghị các Bên tham gia Công ước khung của Liên hợp quốc về biến đổi khí hậu $(\mathrm{COP})$ ủy quyền. 
COP cũng sẽ áp dụng các quy tắc, quy trình và thủ tục phải tuân thủ khi thực hiện các hoạt động theo Điều 6.4. Điều này sẽ đảm bảo rằng toàn bộ thiết kế dự án, quá trình thực hiện các hoạt động giảm nhẹ cũng như xác minh giảm nhẹ phát thải đều đạt yêu cầu tiêu chuẩn đề ra. Cũng như hợp tác theo Điều 6.2, việc giảm phát thải đạt được với cơ chế Điều 6.4 ở một quốc gia có thể được chuyển sang một quốc gia khác và được tính vào NDC [8]. Điều 6.8 đề cập các phương thức phi thị trường.

Trong giai đoạn sau 2020, khi Thỏa thuận Paris về biến đổi khí hậu bước vào giai đoạn thực hiện, Cơ chế JCM sẽ trở thành một trong những phương thức hợp tác song phương dầu tiên thuộc khuôn khổ Điều 6.2. Đồng thời, Cơ chế JCM cũng sẽ phải có những sự điều chỉnh nhất định để phù hợp với các quy định thuộc Thỏa thuận Paris [9]. Chính vì vậy, việc đánh giá mối liên hệ giữa Cơ chế JCM và các cơ chế thuộc Điều 6 của Thỏa thuận Paris sẽ phục vụ việc đánh giá tiềm năng thực hiện Cơ chế JCM tại Việt Nam trong tương lai.

Một trong những yêu cầu chính trong Điều 6.2 là phải thiết lập hệ thống kiểm kê chặt chẽ, liên kết đảm bảo có được sự điều chỉnh kết quả giảm nhẹ tương ứng (corresponding adjustment). Các điều chỉnh kết quả giảm nhẹ tương ứng được thực hiện trên nguyên tắc rằng tất cả các kết quả trao đổi quốc tế về giảm nhẹ phải được phản ánh bằng việc điều chỉnh giảm trừ ở một quốc gia và điều chỉnh bổ sung ở một quốc gia khác, do đó tránh được việc cùng một kết quả giảm nhẹ nhưng sẽ được báo cáo hai lần. Đây cũng là một thách thức lớn trong quá trình triển khai cấp tín chỉ của Cơ chế JCM. Các dự án thuộc Cơ chế JCM trong thời gian thực hiện sẽ được Ủy ban Hỗn hợp cấp tín chỉ qua 2 lần. Lần đầu là kể từ 1 năm sau khi dự án được đăng ký và thực hiện. Lần thứ hai là sau khi dự án kết thúc. Việc không quy định thời gian thực, cụ thể để công nhận các kết quả giảm nhẹ sẽ có thể việc trùng lặp báo cáo kết quả giảm nhẹ của các quốc gia. Như vậy, để tránh trùng lặp, Việt Nam và Nhật Bản cần thống nhất các quy định chung về thời gian, phạm vi báo cáo các kết quả giảm nhẹ thuộc Cơ chế JCM [8].

Điều 6.2 cũng quy định rằng nếu các quốc gia muốn sử dụng các kết quả trao đổi quốc tế về giảm nhẹ (ITMO), cần chứng minh các tiêu chí về phát triển bền vững, tính toàn vẹn môi trường và tính minh bạch được đảm bảo. Hiện nay, khi Việt Nam tham gia Cơ chế JCM đã được phía Nhật Bản hỗ trợ xây dựng một hệ thống đăng ký và lưu trữ thông tin tín chỉ, tạm thời đáp ứng các yêu cầu về tính minh bạch. Tuy nhiên, đóng góp của các dự án JCM về phát triển bền vững hay toàn vẹn môi trường là chưa rõ ràng. Chính vì vậy, trong thời gian tới, cũng cần xây dựng thêm các tiêu chí, phương thức đánh giá tác động môi trường, phát triển bền vững trong quá trình xây dựng và phê duyệt đăng ký dự án JCM.

\section{Kết quả}

\subsection{Tình hình thực hiện Co chế JCM tại Việt Nam}

Việt Nam là một trong những quốc gia đầu tiên ký kết tham gia Cơ chế tín chỉ chung JCM với Nhật Bản, được thể hiện qua Bản ghi nhớ hợp tác về Tăng trưởng các-bon thấp giữa Việt Nam và Nhật Bản, ký lần đầu vào ngày $02 / 7 / 2013$ và ký lần thứ hai ngày $01 / 7 / 2017$ [10-11]. Ngày 06/4/2015, Bộ trưởng Bộ Tài nguyên và Môi trường đã ban hành Thông tư số 17/2015/TT-BTNMT quy định việc xây dựng và thực hiện dự án theo Cơ chế tín chỉ chung trong khuôn khổ hợp tác về Tăng trưởng các-bon thấp giữa Việt Nam - Nhật Bản [12].

Để chỉ đạo, điểu phối và quản lý các hoạt động thực hiện Cơ chế JCM, một Ủy ban Hỗn hợp với thành viên từ các bộ, ngành liên quan của chính phủ Việt Nam và Nhật Bản cùng tham gia, bao gồm 18 thành viên, 6 từ phía Nhật Bản và 12 từ phía Việt Nam Từ năm 2013 đến nay, Ủy ban hỗn hợp hai nước Việt Nam và Nhật Bản đã tiến hành tổ chức họp 8 lần (năm 2015 đã tổ chức họp 02 lần vào tháng 1 và tháng 8 ). Các biểu mẫu liên quan được thông qua lần đầu trong cuộc họp lần thứ 2 năm 2014 tại Tokyo và được thông qua sửa đổi trong cuộc họp lần thứ 5 năm 2016 tại Hà Nội. 
Quy trình thực hiện dự án JCM tại Việt Nam cũng tương đồng với các nước đối tác tham gia cơ chế và gồm 7 bước chính: (1) Xây dựng phương pháp luận (Ủy ban Hỗn hợp thông qua); (2) Xây dựng tài liệu thiết kế dự án (PDD); (3) Thẩm định dự án (Bên thứ ba (TPE) thực hiện); (4) Đăng ký dự án (Ủy ban hỗn hợp quyêt định); (5) Giám sát hoạt động dự án (Bên thứ ba thực hiện); (6) Thẩm tra (Bên thứ ba thực hiện); (7) Cấp tín chỉ (Ủy ban hỗn hợp quyết định).

Hiện nay, tổng cộng có 7 đơn vị được công nhận và hoạt động với tư cách Bên thứ ba hoạt động thẩm định cho các dự án theo Cơ chế JCM tại Việt Nam. Để trở thành Bên thứ ba trong Cơ chế JCM, tổ chức, cơ quan cần đủ điều kiện sau: (1) Được công nhận theo tiêu chuẩn ISO 14065 bởi một cơ quan công nhận là thành viên của Diễn đàn Công nhận quốc tế dựa theo tiêu chuẩn ISO 14.064-2; hoặc (2) là Cơ quan nghiệp vụ chuyên trách (DOE) hoặc cơ quan nghiệp vụ được chứng nhận bởi Ban Điều hành thuộc Cơ chế phát triển sạch. Các đơn vị đăng ký trở thành Bên thứ ba có trách nhiệm nộp hồ sơ để Ủy ban Hỗn hợp xét duyệt và công nhận.

Chính phủ hai nước Việt Nam và Nhật Bản cũng đã phê duyệt 15 phương pháp luận tạo tiền đề cho các cơ quan, đơn vị áp dụng xây dựng và đăng ký các dự án. Các phương pháp luận tập trung vào lĩnh vực năng lượng tái tạo, tiết kiệm năng lượng và đều do các công ty của Nhật Bản nghiên cứu, đề xuất. So với các quốc gia tham gia thực hiện Cơ chế JCM với Nhật Bản, Việt Nam có số lượng phương pháp luận nhiều thứ 2 sau In-đô-nê-xia với 19 phương pháp luận.

Tính đến năm 2020, đã có 14 dự án được đăng ký với tiềm năng giảm phát thải khí nhà kính đạt 15.996 tCO2 tương đương/năm. Việt Nam có số dự án được đăng ký nhiều thứ $2 \mathrm{sau}$ In-đô-nê-xia với 19 dự án. Danh mục các dự án được đăng ký tại Bảng 1 . Trong số 14 dự án được đăng ký, có 11 dự án nhận được tài trợ từ Bộ Môi trường Nhật Bản và 03 dự án nhận được tài trợ từ Bộ Kinh tế, Thương mại và Công nghiệp Nhật Bản. Tổng kinh phí được nhận là gần 35 triệu USD, chiếm $38 \%$ tổng kinh phí thực hiện các dự án.

Bảng 1. Thông tin các dự án JCM tại Việt Nam [1].

\begin{tabular}{|c|c|c|c|c|c|c|}
\hline STT & Dụ̣ án & $\begin{array}{c}\text { Tổng vốn } \\
\text { (USD) }\end{array}$ & $\begin{array}{c}\text { Hỗ trọ̣ từ } \\
\text { Chính phủ } \\
\text { Nhật Bản } \\
\text { (USD) }\end{array}$ & $\begin{array}{c}\text { Lượng tín } \\
\text { chỉ }\end{array}$ & $\begin{array}{c}\text { Lượng tín } \\
\text { chỉ phân bổ } \\
\text { phía Việt } \\
\text { Nam }\end{array}$ & $\begin{array}{c}\text { Lượng tín } \\
\text { chỉ phân bổ } \\
\text { phía Nhật } \\
\text { Bản }\end{array}$ \\
\hline 1 & $\begin{array}{l}\text { Lái xe sinh thái thông } \\
\text { qua sử dụng bộ đo tốc } \\
\text { độ điện tử }\end{array}$ & 456.620 & 224.860 & 288 & 58 & 230 \\
\hline 2 & $\begin{array}{l}\text { Thúc đẩy bệnh viện } \\
\text { xanh thông qua tăng } \\
\text { cường hiệu quả năng } \\
\text { lượng/môi trường tại } \\
\text { các bệnh viện quốc } \\
\text { gia tại Việt Nam }\end{array}$ & 7.187 .881 & 4.930 .869 & 878 & 193 & 685 \\
\hline 3 & $\begin{array}{l}\text { Dự án khách sạn } \\
\text { các-bon thấp ở Việt } \\
\text { Nam: Nâng cao hiệu } \\
\text { suất năng lượng của } \\
\text { các tòa nhà thương } \\
\text { mại bằng cách sử }\end{array}$ & 316.756 & 316.756 & 261 & 80 & 181 \\
\hline
\end{tabular}




\begin{tabular}{|c|c|c|c|c|c|c|}
\hline STT & Dự án & $\begin{array}{c}\text { Tổng vốn } \\
\text { (USD) }\end{array}$ & $\begin{array}{l}\text { Hỗ trọ̣ từ } \\
\text { Chính phủ } \\
\text { Nhật Bản } \\
\text { (USD) }\end{array}$ & $\begin{array}{l}\text { Lượng tín } \\
\text { chỉ }\end{array}$ & $\begin{array}{l}\text { Lượng tín } \\
\text { chỉ phân bổ } \\
\text { phía Việt } \\
\text { Nam } \\
\end{array}$ & $\begin{array}{c}\text { Lượng tín } \\
\text { chỉ phân bổ } \\
\text { phía Nhật } \\
\text { Bản }\end{array}$ \\
\hline 4 & $\begin{array}{l}\text { dụng các thiết bị hiệu } \\
\text { suất cao } \\
\text { Sử dụng biến áp lõi } \\
\text { thép vô định hình } \\
\text { hiệu năng cao trong } \\
\text { hệ thống truyền tải } \\
\text { điện năng ở miền } \\
\text { Nam Việt Nam } \\
\text { Lắp đặt điều hòa }\end{array}$ & 27.191 .480 & 8.682 .240 & 151 & 75 & 76 \\
\hline 5 & $\begin{array}{l}\text { không khí hiệu suất } \\
\text { cao tại các khách sạn }\end{array}$ & 1.130 .841 & 565.420 & 189 & 56 & 133 \\
\hline 6 & $\begin{array}{l}\text { Tiết kiệm năng lượng } \\
\text { và nâng cao hiệu suất } \\
\text { làm việc bằng cách } \\
\text { giới thiệu hệ thống } \\
\text { đèn LED mới với } \\
\text { công nghệ chip trên } \\
\text { bo mạch chủ ở Việt } \\
\text { Nam }\end{array}$ & 3.406 .596 & 3.234 .815 & 143 & 15 & 128 \\
\hline 7 & $\begin{array}{l}\text { Lắp đặt hệ thống điện } \\
\text { năng lượng mặt trời ở } \\
\text { các Trung Tâm } \\
\text { Thương Mại tại TP. } \\
\text { Hồ Chí Minh }\end{array}$ & 605.066 & 302.530 & $\begin{array}{l}\text { Chưa được } \\
\text { cấp }\end{array}$ & $\begin{array}{l}\text { Chưa được } \\
\text { cấp }\end{array}$ & $\begin{array}{l}\text { Chưa được } \\
\text { cấp }\end{array}$ \\
\hline 8 & $\begin{array}{l}\text { Đề xuất lắp đặt máy } \\
\text { biến áp vô định hình } \\
\text { hiệu suất cao trên } \\
\text { mạng lưới phân phối } \\
\text { điện tại khu vực miền } \\
\text { Trung và miền Nam } \\
\text { Việt Nam }\end{array}$ & 27.191 .484 & 8.682 .210 & 2.477 & 1238 & 1.239 \\
\hline 9 & $\begin{array}{l}\text { Đề xuất lắp đặt máy } \\
\text { điều hòa tiết kiệm } \\
\text { năng lượng tại Công } \\
\text { ty TNHH Sản Phẩm } \\
\text { RICOH Imaging Việt } \\
\text { Nam }\end{array}$ & 331.366 & 165.680 & 28 & 9 & 19 \\
\hline 10 & $\begin{array}{l}\text { Lắp ráp vỏ bình ắc } \\
\text { quy tại nhà máy ắc }\end{array}$ & 3.908 .335 & 1.954 .150 & $\begin{array}{l}\text { Chưa được } \\
\text { cấp }\end{array}$ & $\begin{array}{l}\text { Chưa được } \\
\text { cấp }\end{array}$ & $\begin{array}{c}\text { Chưa được } \\
\text { cấp }\end{array}$ \\
\hline
\end{tabular}




\begin{tabular}{|c|c|c|c|c|c|c|}
\hline STT & Dự án & $\begin{array}{c}\text { Tổng vốn } \\
\text { (USD) }\end{array}$ & $\begin{array}{l}\text { Hỗ trọ̣ từ } \\
\text { Chính phủ } \\
\text { Nhật Bản } \\
\text { (USD) }\end{array}$ & $\begin{array}{c}\text { Lượng tín } \\
\text { chỉ }\end{array}$ & $\begin{array}{l}\text { Lượng tín } \\
\text { chỉ phân bổ } \\
\text { phía Việt } \\
\text { Nam }\end{array}$ & $\begin{array}{c}\text { Lượng tín } \\
\text { chỉ phân bổ } \\
\text { phía Nhật } \\
\text { Bản }\end{array}$ \\
\hline & $\begin{array}{l}\text { quy axit chì của công } \\
\text { ty TNHH Công Nghệ } \\
\text { Năng Lượng Hóa } \\
\text { Học Hitachi Việt } \\
\text { Nam }\end{array}$ & & & & & \\
\hline 11 & $\begin{array}{l}\text { Lắp đặt các thiết bị } \\
\text { tiết kiệm năng lượng } \\
\text { tại nhà máy Lens }\end{array}$ & 497.797 & 248.880 & $\begin{array}{l}\text { Chưa được } \\
\text { cấp }\end{array}$ & $\begin{array}{l}\text { Chưa được } \\
\text { cấp }\end{array}$ & $\begin{array}{l}\text { Chưa được } \\
\text { cấp }\end{array}$ \\
\hline 12 & $\begin{array}{l}\text { Đề xuất lắp đặt máy } \\
\text { bơm nước hiệu suất } \\
\text { cao tại thành phố Đà } \\
\text { Nẵng }\end{array}$ & 1.329 .037 & 664.510 & $\begin{array}{l}\text { Chưa được } \\
\text { cấp }\end{array}$ & $\begin{array}{l}\text { Chưa được } \\
\text { cấp }\end{array}$ & $\begin{array}{c}\text { Chưa được } \\
\text { cấp }\end{array}$ \\
\hline 13 & $\begin{array}{l}\text { Đề xuất lắp đặt máy } \\
\text { biến áp vô định hình } \\
\text { hiệu suất cao trên } \\
\text { mạng lưới phân phối } \\
\text { điện tại khu vực miền } \\
\text { Bắc, miền Trung và } \\
\text { miền Nam Việt Nam }\end{array}$ & 15.771 .765 & 4.731 .520 & $\begin{array}{l}\text { Chưa được } \\
\text { cấp }\end{array}$ & $\begin{array}{l}\text { Chưa được } \\
\text { cấp }\end{array}$ & $\begin{array}{l}\text { Chưa được } \\
\text { cấp }\end{array}$ \\
\hline 14 & $\begin{array}{l}\text { Lắp đặt máy bện dây } \\
\text { cáp tiết kiệm năng } \\
\text { lượng tại nhà máy } \\
\text { công ty TNHH } \\
\text { YAZAKI EDS Việt } \\
\text { Nam }\end{array}$ & 1.813 .379 & 362.630 & $\begin{array}{l}\text { Chưa được } \\
\text { cấp }\end{array}$ & $\begin{array}{l}\text { Chưa được } \\
\text { cấp }\end{array}$ & $\begin{array}{l}\text { Chưa được } \\
\text { cấp }\end{array}$ \\
\hline $\begin{array}{l}\text { E } \\
\text { tín ch } \\
\text { các- } \mathrm{b} \\
\text { khi cl } \\
\text { Việt I } \\
\mathrm{S} \\
\text { Bên tl } \\
\text { với c } \\
\text { Nhật } \\
\text { Phần } \\
\text { phân } \\
\text { chuyê }\end{array}$ & $\begin{array}{l}\text { ến nay, đã có } 6 \text { dự án } \\
\text { ỉ các-bon. Ûy ban } \mathrm{h} \\
\text { on, tương đương với } \\
\text { ưa có dự án. Lượng } \\
\text { Jam và các đơn vị th } \\
\text { ố lượng tín chỉ các-- } \\
\text { lam gia và được quy, } \\
\text { íc dự án đã được cấ } \\
\text { Bản từ } 50-90 \% \text {, Chír } \\
\text { tín chỉ các-bon mà } \\
\text { bổ thông thường là } \\
n \text { phần này vào tài } \mathrm{k}\end{array}$ & $\begin{array}{l}\text { đi vào hoạt } \\
\text { n hợp hai } \mathrm{n} \\
\text { t.415 tấn } \mathrm{CC} \\
\text { n chỉ các- } \mathrm{b} \\
\text { m gia dự án } \\
\text { on phân bổ } \\
\text { tịnh tại các } \\
\text { tín chỉ các- } \\
\text { h phủ Việt I } \\
\text { hính phủ } \mathrm{N} \\
\text { o một số đo } \\
\text { oản của Ch }\end{array}$ & $\begin{array}{l}\text { ong và được } \\
\text { óc đã xem x } \\
\text { tđ cắt giảm } \\
\text { được phân } \\
\text { n các Bên c } \\
\text { uộc họp Ủy } \\
\text { on, lượng } \\
\text { m từ 10-30 } \\
\text { ật Bản và V } \\
\text { vị tham gi } \\
h \text { phủ. }\end{array}$ & $\begin{array}{l}\text { Im sát, thẩr } \\
\text { và cấp tồn } \\
\text { ợc so với lu } \\
\text { cho Chính } \\
\text { c đề xuất t } \\
\text { n hỗn hợp } \\
\text { chỉ các-bo } \\
\text { các đơn vị } \\
\text { Nam nhậr } \\
\text { ự án khôn }\end{array}$ & $\begin{array}{l}\text { tra số liệu ho } \\
\text { cộng đã có } \\
\text { ong phát thải } \\
\text { phủ Nhật Bả } \\
\text { eo mức đóng } \\
\text { ằng năm. Trê } \\
\text { phân bồ ch } \\
\text { ham gia dự á } \\
\text { được hơn so } \\
\text { nhận tín chi }\end{array}$ & $\begin{array}{l}\text { teộng, cấp } \\
415 \text { tín chỉ } \\
\text { hí nhà kính } \\
\text { Chính phủ } \\
\text { góp của các } \\
\text { thực tế đối } \\
\text { Chính phủ } \\
\text { từ } 0-40 \% \text {. } \\
\text { với tiêu chí } \\
\text { các-bon và }\end{array}$ \\
\hline
\end{tabular}

\section{2. Đánh giá tình hình thục hiện Co chế JCM tại Việt Nam}

3.2.1. Thành tựu 
Việc tham gia Cơ chế JCM trong thời gian qua đã góp phần thúc đẩy thực hiện Tuyên bố giữa Việt Nam và Nhật Bản về phát triển toàn diện quan hệ đối tác chiến lược vì hòa bình và phồn vinh ở Châu Á (31/10/2010), góp phần thắt chặt quan hệ ngoại giao giữa hai chính phủ, giúp kích thích đầu tư vào Việt Nam từ các nhà đầu tư Nhật Bản và tăng cường quan hệ thương mại giữa hai nước.

Trong bối cảnh Việt Nam trong giai đoạn trước 2020 vẫn thực hiện giảm nhẹ phát thải khí nhà kính theo hình thức tự nguyện, việc thực hiện các hoạt động theo Cơ chế JCM tại Việt Nam đã giúp tạo ra một kênh đầu tư mới cho các hoạt động giảm nhẹ phát thải khí nhà kính; các doanh nghiệp được tiếp cận và áp dụng các công nghệ, sản phẩm, hệ thống, dịch vụ các-bon thấp tiên tiến của Nhật Bản và được tăng cường năng lực trong thực hiện các hoạt động giảm nhẹ phát thải khí nhà kính theo tiêu chuẩn quốc tế. Bộ Tài nguyên và Môi trường có thêm kinh nghiệm trong xây dựng, quản lý hệ thống đăng ký các dự án JCM, lượng tín chỉ các-bon được cấp cho các dự án JCM để tiến tới xây dựng hệ thống đăng ký các hoạt động giảm nhẹ phát thải khí nhà kính phục vụ mục tiêu giảm nhẹ theo cam kết tại NDC của Việt Nam trong giai đoạn 2021-2030.

Doanh nghiệp tại Việt Nam tham gia Cơ chế JCM cũng đã được tiếp cận và áp dụng các công nghệ, sản phẩm, hệ thống, dịch vụ các-bon thấp tiên tiến của Nhật Bản; tạo cơ sở cho việc chuyển đổi từ công nghệ gây phát thải nhiều khí nhà kính sang công nghệ ít phát thải, đóng góp cho sự phát triển bền vững tại Việt Nam. Doanh nghiệp tại Việt Nam được tăng cường năng lực trong thực hiện các hoạt động giảm nhẹ phát thải khí nhà kính như: xây dựng, áp dụng phương pháp luận; cách thức đo đạc, báo cáo thông tin, số liệu theo tiêu chuẩn quốc tế (MRV).

\subsubsection{Tồn tại, hạn chế}

Tuy nhiên, quá trình tham vấn các đơn vị liên quan cũng chỉ ra rằng việc thực hiện Cơ chế JCM trong thời gian qua vẫn còn một số tồn tại và thách thức nhất định. Về phương diện quản lý, chính sách, Việt Nam vẫn chưa có quy định cụ thể về chế độ báo cáo tình hình thực hiện dự án đối với các bên tham gia dự án, chế tài xử lý vi phạm đối với hoạt động thực hiện dự án JCM.

Về triển khai thực hiện dự án, các dự án thực hiện đòi hỏi phải áp dụng công nghệ tiên tiến của Nhật Bản, chi phí lớn. Khi mở rộng quy mô thực hiện sẽ là gánh nặng chi phí cho doanh nghiệp Việt Nam vì chỉ được hỗ trợ nhiều trong giai đoạn đầu tư ban đầu hoặc thí điểm. Một số dự án muốn triển khai giai đoạn tiếp theo chỉ nhận được hỗ trợ tối đa khoảng $30 \%$ và tiếp theo chỉ khoảng $17 \%$ chi phí thực hiện từ nguồn hồ trợ của Bộ Môi trường Nhật Bản. Lượng giảm phát thải khí nhà kính chưa tương xứng với chi phí đầu tư. Các dự án JCM giai đoạn vừa qua là các dự án thực hiện ở quy mô thí điểm, hoặc dự án kiểu mẫu, nên mức đóng góp giảm phát thải còn hạn chế.

Nhiều doanh nghiệp tham gia dự án JCM, đặc biệt là các doanh nghiệp vốn đầu tư Nhật Bản hoạt động tại Việt Nam không có kiến thức về Cơ chế JCM, xác định việc tham gia dự án vì được nhận một khoản hỗ trợ tương đối lớn so với tổng kinh phí thực hiện dự án, không quan tâm tới việc khi thực hiện dự án sẽ góp phần giảm nhẹ phát thải khí nhà kính và nhận được tín chỉ các-bon. Các cơ quan, doanh nghiệp Việt Nam thiếu thông tin về Cơ chế JCM. Hiện nay, các dự án đang đề xuất và được đăng ký theo Cơ chế JCM tại Việt Nam đều do các doanh nghiệp và công ty tư vấn Nhật Bản chủ động tìm kiếm và tiếp cận với các đối tác tại Việt Nam.

Tham vấn các chuyên gia và đơn vị tư vấn cũng cho thấy chi phí phải trả cho đơn vị tư vấn phía Nhật Bản để nghiên cứu, xây dựng và giám sát triển khai dự án chiếm tỉ trọng lớn so với hỗ trợ nhận được. Thông thường, các bên tham gia dự án phải trả cho đơn vị tư vấn phía Nhật Bản $10 \%$ giá trị hỗ trợ nhận được. Đồng thời, Khung hướng dẫn xây dựng phương pháp luận áp dụng cách tính lượng giảm phát thải theo hướng quá an toàn nên lượng giảm phát thải đạt được của dự án nhận được ít hơn so với thực tế. 


\section{Kết luận}

Thông qua đánh giá, có thể kết luận việc thực hiện Cơ chế JCM sẽ góp phần giúp Việt Nam đạt được mục tiêu giảm nhẹ trong NDC. Ngoài ra, Cơ chế JCM sẽ góp phần thúc đẩy sự phát triển của một xã hội các-bon thấp và kinh nghiệm thực hiện JCM sẽ giúp Việt Nam xây dựng, phát triển thị trường các-bon trong nước. Tuy nhiên, để triển khai các hoạt động theo Cơ chế JCM có hiệu quả trong giai đoạn tới, tạo tiền đề triển khai các cơ chế trong khuôn khổ Điều 6 của Thỏa thuận Paris, vẫn cần phải giải quyết các tồn tại và thách thức trong thực hiện Cơ chế JCM tại Việt Nam, đồng thời cần có các chỉnh sửa, bổ sung quy định phù hợp với các quy định quốc tế. Chính phủ Việt Nam cũng cần tăng cường hoạt động nâng cao năng lực cho các doanh nghiệp trong việc tiếp cận, xây dựng và thực hiện các dự án JCM và các dự án thuộc các cơ chế tạo tín chỉ khác; tăng cường năng lực và khuyến khích cho các cơ quan, đơn vị tại Việt Nam tham gia vào hoạt động tư vấn cũng như thẩm định các dự án JCM; và tăng cường công tác quản lý nhà nước, kiểm tra, giám sát định kỳ các dự án. Đồng thời, Chính phủ hai nước cũng cần có thêm các quy định cụ thể để xác định tỷ lệ phân chia tín chỉ để đảm bảo quyền lợi công bằng giữa các bên tham gia dự án.

Đóng góp của tác giả: Xây dựng ý tưởng nghiên cứu: N.T.C., T.T.D.; Lựa chọn phương pháp nghiên cứu: N.T.C., T.T.D.; Xử lý số liệu: T.T.D.; Viết bản thảo bài báo: N.T.C.; Chỉnh sửa bài báo: T.T.D.

Lời cảm ơn: Tập thể tác giả xin trân trọng cảm ơn Tổ Thư ký Cơ chế JCM tại Việt Nam và Phòng Kinh tế và Thông tin biến đổi khí hậu, Cục Biến đổi khí hậu, Bộ Tài nguyên và Môi trường đã hỗ trợ về số liệu và thông tin để thực hiện bài báo này.

Lời cam đoan: Tập thể tác giả cam đoan bài báo này là công trình nghiên cứu của tập thể tác giả, chưa được công bố ở đâu, không được sao chép từ những nghiên cứu trước đây; không có sự tranh chấp lợi ích trong nhóm tác giả.

\section{Tài liệu tham khảo}

1. The Joint Crediting Mechanism (JCM). Avaliable online: https://www.jcm.go.jp/.

2. Global Environment Centre Foundation (GEC). Avaliable online: http://gec.jp/jcm/.

3. Global Environmental Centre Foundation. Guidelines for Submitting Proposals, 2019, Avaliable online:

http://gec.jp/jcm/jp/kobo/h31/mp/(tentative)2019_Guidelines_for_Submitting_Prop osals.pdf.

4. New Energy and Industrial Technology Development Organization (NEDO). Avaliable online: https://www.nedo.go.jp/english/publications reports index.html.

5. Bộ Tài nguyên và Môi trường. Báo cáo Đóng góp do quốc gia tự quyết định (NDC), 2015.

https://www4.unfccc.int/sites/ndestaging/PublishedDocuments/Viet $\% 20 \mathrm{Nam} \% 20 \mathrm{Fi}$ rst/VIETNAM\%27S\%20INDC.pdf.

6. Điều 6 của Thỏa thuận Paris về biến đổi khí hậu. Trang online: https://unfccc.int/process-and-meetings/the-paris-agreement/the-paris-agreement.

7. Asadnabizadeh, M. Development of UN Framework Convention on Climate Change Negotiations under COP25: Article 6 of the Paris Agreement perspective. Open Political Sci. 2019, 2, 113-119. https://doi.org/10.1515/openps-2019-0012.

8. ADB. Decoding Article 6 of the Paris Agreement. 2018, Publication Stock No. TIM189218-2, pp. 132. http://dx.doi.org/10.22617/TIM189218-2.

9. Müller, B.; Michaelowa, A. How to operationalize accounting under Article 6 market mechanisms of the Paris Agreement. Clim. Policy 2019, 19, 1-8. https://doi.org/10.1080/14693062.2019.1599803. 
10. Bản ghi nhớ hợp tác về Tăng trưởng các-bon thấp giữa Việt Nam và Nhật Bản, 2013. Trang online: https://www.jcm.go.jp/rules_and_guidelines/histories/41/JCM_VN_bilateral_docu ment.pdf.

11. Bản ghi nhớ hợp tác về Tăng trưởng các-bon thấp giữa Việt Nam và Nhật Bản, 2017. Trang online: https://www.jcm.go.jp/rules and guidelines/histories/262/JCM VN bilateral docu ment 01June2017.pdf.

12. Thông tư 17/2015/TT-BTNMT ngày 06/04/2015 của Bộ trưởng Bộ Tài nguyên và Môi trường quy định việc xây dựng và thực hiện dự án theo Cơ chế JCM, 2015. Trang online:

http://vanban.chinhphu.vn/portal/page/portal/chinhphu/hethongvanban?class_id=1\& page $=77 \&$ mode $=$ detail \&document $\mathrm{id}=179864$

\title{
Evaluation of implementation of JCM in Viet Nam: Experiences to Operationalize the Article 6 of the Paris Agreement
}

\author{
Nguyen Thanh Cong1, Tran Tien Dzung ${ }^{2}$ \\ 1 Department of Climate Change; tcongnguyen90@gmail.com \\ 2 Viet Nam Meteorology and Hydrological Administration; tdung117@gmail.com
}

\begin{abstract}
In its Nationally Determined Contribution (NDC), Viet Nam commits to reduce its greenhouse gas emission by $8 \%$ using domestic resources and could reduce up to $25 \%$ if receiving international financial supports, transfer of technology and capacity building through bilateral and multilateral cooperation activities, and implementating mechanisms under the Paris Agreement. The Joint Crediting Mechanism (JCM) is a prime example of a bilateral cooperation approach under Article 6.2 within the Paris Agreement. The paper will provide information and evaluate the status of the implementation of the JCM in Viet Nam, as well as analyze the relationship between the JCM and Article 6 of the Paris Agreement. From there, the results of the article will provide a basis for policy makers in developing relevant legal documents, preparing for the implementation of new mechanisms under the Paris Agreement, contributing to Viet Nam's international commitment to reducing greenhouse gas emissions.
\end{abstract}

Keywords: Joint Crediting Mechanism; Greenhouse gas emission reduction; Paris Agreement. 